\title{
Diagnostic accuracy of manual office blood pressure measurement in ambulatory hypertensive patients in Korea
}

\author{
Sehun Kim ${ }^{1, \star}$, Jin Joo Park ${ }^{1,}$, Seung-Ah Lee ${ }^{2}$, Youngjin Cho ${ }^{1}$, Yeonyee E. Yoon ${ }^{1}$, Il-Young Oh ${ }^{1}$, \\ Chang-Hwan Yoon ${ }^{1}$, Jung-Won Suh' ${ }^{1}$, Young-Seok Cho ${ }^{1}$, Tae-Jin Youn ${ }^{1}$, Goo-Yeong Cho ${ }^{1}$, In-Ho Chae ${ }^{1}$, \\ Hae-Young Lee ${ }^{3}$, Jinho Shin ${ }^{4}$, Sungha Park ${ }^{5}$ and Dong-Ju Choi ${ }^{1}$
}

\begin{abstract}
${ }^{1}$ Department of Internal Medicine, Seoul National University Bundang Hospital, Seongnam; ${ }^{2}$ Department of Internal Medicine, National Medical Center, Seoul; ${ }^{3}$ Department of Internal Medicine, Seoul National University Hospital, Seoul; ${ }^{4}$ Department of Internal Medicine, Hanyang University Seoul Hospital, Seoul; ${ }^{5}$ Department of Internal Medicine, Severance Hospital, Yonsei University College of Medicine, Seoul, Korea
\end{abstract}

Received: May 11, 2016 Revised : September 4, 2016 Accepted: October 5, 2016

\section{Correspondence to \\ Dong-Ju Choi, M.D. \\ Department of Internal Medicine, Seoul National University Bundang Hospital, 82 Gumi-ro 173beon-gil, Bundang-gu, Seongnam 13620, Korea \\ Tel: +82-31-787-7007 \\ Fax: +82-31-787-7041 \\ E-mail: djchoi@snubh.org \\ *'These authors contributed equally to this work.}

Background/Aims: Currently, office blood pressure (OBP) is the most widely used method of measuring blood pressure (BP) in daily clinical practice. However, data on the diagnostic accuracy of OBP in reference to ambulatory blood pressure (ABP) are scarce in Korea.

Methods: In retrospective and prospective cohorts, manual OBP and ABP measurements were compared among ambulatory hypertensive patients. Hypertension was defined as systolic $\mathrm{OBP} \geq 140 \mathrm{mmHg}$ and/or diastolic $\mathrm{OBP} \geq 90 \mathrm{mmHg}$, and systolic $\mathrm{ABP} \geq 130 \mathrm{mmHg}$ and/or diastolic $\mathrm{ABP} \geq 80 \mathrm{mmHg}$.

Results: In the retrospective cohort $(n=903)$, the mean OBP1 (before ABP measurement) was higher than $\mathrm{ABP}$ in both systolic (138 $\pm 17 \mathrm{mmHg}$ vs. $123 \pm 13$ $\mathrm{mmHg}, p<0.001)$ and diastolic $(84 \pm 12 \mathrm{mmHg}$ vs. $78 \pm 11 \mathrm{mmHg}, p<0.001)$ measurements. Interestingly, there was only a weak correlation between OBP and ABP $\left(r^{2}=0.038, p<0.001\right)$. The overall discordance rate of OBP compared to ABP, which is the reference method for measuring BP, was $43.9 \%$. The prospective cohort $(\mathrm{n}=$ 57) showed similar results. In a subgroup analysis, male patients had higher false negative results (masked or under-treated hypertension) than did female patients ( $26.1 \%$ vs. $17.8 \%, p=0.003$ ), whereas female patients had a higher false positive rate (white-coat or over-treated hypertension) than did male patients (28.7\% vs. $15.2 \%$, $p<0.001)$.

Conclusions: The diagnostic accuracy of manual OBP is low in reference to ABP. Men and women have different patterns of discordance. These findings indicate that management of hypertensive patients with manual OBP measurements may be suboptimal and encourages the use of $\mathrm{ABP}$ in ambulatory hypertensive patients.

Keywords: Manual office blood pressure; Ambulatory blood pressure; Diagnostic accuracy; Sex

\section{INTRODUCTION}

Hypertension is common and, is increasing in preva- lence and is an important risk factor for cardiovascular disease [1,2]. Previous epidemiological studies have demonstrated a strong relationship between blood 
pressure (BP) and coronary artery disease, stroke, heart failure, renal failure, and death, making correct management of BP essential [3,4]. Therefore, a reliable assessment of BP is central to optimal hypertension treatment. Manual BP measurement is the most widely used method of measuring BP in the clinic [5]. However, measuring $\mathrm{BP}$ according to the best practice guidelines can be challenging due to the complexity of the measuring technique and the circumstances in the outpatient clinic [6]. In addition, masked and nocturnal hypertension, as well as the white coat phenomenon can limit the use of the office blood pressure (OBP) measurement $[7,8]$. Consequently, there may be differences between OBP and ambulatory blood pressure (ABP) measurement $[9,10]$. Thus, recent guidelines recommend the implementation of ABP in clinical practice [7,11-15]. However, there have been few studies on the relationship between OBP and ABP in Korean populations $[16,17]$.

In the present study, we evaluated the diagnostic accuracy of manual OBP in reference to ABP in both prospective and retrospective cohorts of ambulatory hypertensive patients.

\section{METHODS}

In the retrospective cohort, we examined all ambulatory patients who underwent both manual OBP and $\mathrm{ABP}$ measurements from January to December 2013. In the prospective cohort, we consecutively enrolled patients who were on treatment for, or newly diagnosed with, hypertension in the outpatient clinic from January through May 2014. The study was approved by the Institutional Review Board of Seoul National University Bundang Hospital (IRB No: B-1308/216-004). The patients in the prospective cohort provided written informed consent, while the requirement for informed consent was waived for patients in the retrospective cohort by the Institutional Review Board. Hypertension was defined as systolic OBP $\geq 140 \mathrm{mmHg}$ and/or diastolic OBP $\geq 90$ $\mathrm{mmHg}$ and 24-hour average systolic $\mathrm{ABP} \geq 130 \mathrm{mmHg}$ and/or diastolic $\mathrm{ABP} \geq 80 \mathrm{mmHg}$, according to the current hypertension guidelines $[4,18,19]$. Agreement between OBP and ABP was defined as concordance, and disagreement as discordance. White-coat hypertension was defined as untreated patients with OBP $\geq 140 / 90$
mmHg and 24-hour average ABP $<130 / 80 \mathrm{mmHg}$ and awake average $\mathrm{ABP}<135 / 85 \mathrm{mmHg}$ and sleep measurement $<120 / 70 \mathrm{mmHg}$. Over-treated hypertension was defined as patients undergoing hypertension treatment despite exhibiting BP levels above the normal range in a clinical setting (patient's OBP was $>140 / 90 \mathrm{mmHg}$ ), but not in other settings (patient's ABP was in the normal range). Masked hypertension was defined as untreated patients with $\mathrm{OBP}<140 / 90 \mathrm{mmHg}$ and 24 -hour average $\mathrm{ABP} \geq 130 / 80 \mathrm{mmHg}$ and an awake average $\mathrm{ABP} \geq 135 / 85$ $\mathrm{mmHg}$ and sleep measurement $\geq 120 / 70 \mathrm{mmHg}$. Under-treated hypertension was defined as the treatment of patients with hypertension despite exhibiting normal BP level in a clinical setting (patient's OBP was < 140/90 $\mathrm{mmHg}$ ), but exhibit above the normal range during daily living (patient's ABP was above the normal range). $\mathrm{OBP} 1$ and $\mathrm{OBP} 2$ were defined as $\mathrm{BP}$ measured before and after ABP measurement, respectively. Data regarding variables including baseline characteristics, medical history, and medication were obtained.

The primary endpoint of this study was the diagnostic accuracy of $\mathrm{OBP} 1$ in reference to $\mathrm{ABP}$ as the reference method for measuring BP. OBP was measured with a mercury sphygmomanometer (Baumanometer Desk model, W.A. Baum Co. Inc., Copiague, NY, USA) after the patients had rested for at least 5 minutes in a sitting position. ABP monitoring was performed according to the European Society of Hypertension recommendations [20]. We used ABP monitors from two manufacturers (DELMAR-P6, Del Mar Reynolds Medical, Hertford, UK; Mobil-O-Graph NG, I.E.M, Stolberg, Germany). Each BP measurement was performed every 30 minutes during the day and every 60 minutes at night.

Data were expressed as the mean \pm SD for continuous variables and as percentages for categorical variables. Pearson correlation was used to calculate the association between OBP and ABP. A paired $t$ test was used to analyze the difference between $\mathrm{OBP}_{1}$ and $\mathrm{OBP}_{2}$. Receiver operating characteristic (ROC) curve analysis was used to determine the diagnostic power of $\mathrm{OBP}_{1}$ and $\mathrm{OBP}_{2}$. Two-sided $p$ values less than 0.05 were considered statistically significant. Statistical tests were performed using SPSS version 22 (IBM Co., Armonk, NY, USA) and Matlab (Mathworks Inc., Natick, MA, USA). 
Kim S, et al. Diagnostic accuracy of manual office blood pressure

Table 1. Baseline characteristics of retrospective and prospective cohorts

\begin{tabular}{|c|c|c|c|c|c|c|c|c|}
\hline \multirow[b]{2}{*}{ Characteristic } & \multicolumn{4}{|c|}{ Retrospective cohort } & \multicolumn{4}{|c|}{ Prospective cohort } \\
\hline & $\begin{array}{l}\text { All patients } \\
\quad(n=903)\end{array}$ & $\begin{array}{c}\text { On } \\
\text { treatment } \\
(\mathrm{n}=338)\end{array}$ & $\begin{array}{c}\text { Newly } \\
\text { diagnosed } \\
(\mathrm{n}=565)\end{array}$ & $p$ value $^{a}$ & $\begin{array}{l}\text { All patients } \\
(\mathrm{n}=57)\end{array}$ & $\begin{array}{c}\text { On } \\
\text { treatment } \\
(\mathrm{n}=43)\end{array}$ & $\begin{array}{c}\text { Newly } \\
\text { diagnosed } \\
(\mathrm{n}=14)\end{array}$ & $p$ value $^{\mathrm{a}}$ \\
\hline Age & $58.8 \pm 14.1$ & $62.3 \pm 12.4$ & $56.7 \pm 14.6$ & $<0.001$ & $58.6 \pm 15.2$ & $60.3 \pm 15.3$ & $53.5 \pm 14.2$ & 0.137 \\
\hline Male sex & 50.2 & 50.3 & 50.1 & 0.999 & 49.1 & 48.8 & 50 & 0.999 \\
\hline Diabetes mellitus & 15.1 & 21 & 11.5 & $<0.001$ & 15.8 & 20.9 & $\mathrm{o}$ & 0.095 \\
\hline Coronary artery disease & 24.9 & 39.1 & 16.5 & $<0.001$ & 22.8 & $27 \cdot 9$ & 7.1 & 0.152 \\
\hline Cerebrovascular disease & 6.4 & $7 \cdot 1$ & 6.0 & 0.305 & $5 \cdot 3$ & 7.0 & 0 & 0.568 \\
\hline $\mathrm{OBP}_{1}{ }^{\mathrm{b}} \mathrm{SBP}, \mathrm{mmHg}$ & $138.4 \pm 17.8$ & $138.6 \pm 18.5$ & $138.3 \pm 17.4$ & 0.839 & $141.3 \pm 21.2$ & $139.4 \pm 21.4$ & $147.1 \pm 20.1$ & 0.233 \\
\hline $\mathrm{OBP}_{1}{ }^{\mathrm{b}} \mathrm{DBP}, \mathrm{mmHg}$ & $83.7 \pm 11.8$ & $83.0 \pm 11.4$ & $84.1 \pm 12.0$ & 0.173 & $82.0 \pm 12.2$ & $79.4 \pm 10.3$ & $90.2 \pm 14.2$ & 0.017 \\
\hline ABP mean SBP, mmHg & $123.0 \pm 12.8$ & $120.8 \pm 12.5$ & $124 \cdot 3 \pm 12.8$ & $<0.001$ & $125.0 \pm 14.0$ & $122.7 \pm 13.3$ & $132.2 \pm 14.1$ & 0.039 \\
\hline ABP mean DBP, mmHg & $77.7 \pm 10.5$ & $75 \cdot 4 \pm 9.6$ & $79.1 \pm 10.8$ & $<0.001$ & $80.6 \pm 11.7$ & $77.6 \pm 9.5$ & $88.7 \pm 13.6$ & 0.007 \\
\hline $\mathrm{OBP}_{2}{ }^{\mathrm{b}} \mathrm{SBP}, \mathrm{mmHg}$ & $134 \cdot 3 \pm 16 \cdot 5$ & $133.4 \pm 16.6$ & $134 \cdot 9 \pm 16.5$ & 0.213 & $135 \cdot 3 \pm 18.4$ & $133.0 \pm 18.9$ & $143.0 \pm 14.9$ & 0.060 \\
\hline $\mathrm{OBP}_{2}{ }^{\mathrm{b}} \mathrm{DBP}, \mathrm{mmHg}$ & $82.0 \pm 11.2$ & $80.7 \pm 10.9$ & $82.8 \pm 11.3$ & 0.006 & $79.5 \pm 13.1$ & $76.1 \pm 11.5$ & $90.8 \pm 12.1$ & 0.001 \\
\hline \multicolumn{9}{|l|}{ Medication } \\
\hline ACEI & 2.3 & 6.2 & - & - & 1.8 & 6.2 & - & - \\
\hline ARB & 16.5 & 44.1 & - & - & $45 \cdot 6$ & 44.1 & - & - \\
\hline$\beta$-Blocker & 15.0 & 39.9 & - & - & 26.3 & 39.9 & - & - \\
\hline CCB & 23.9 & 63.9 & - & - & 56.1 & 63.9 & - & - \\
\hline Diuretics & 6.9 & 18.3 & - & - & 7 & 18.3 & - & - \\
\hline
\end{tabular}

Values are presented as mean $\pm \mathrm{SD}$ or percentage.

OBP, office blood pressure; SBP, systolic blood pressure; DBP, diastolic blood pressure; ABP, ambulatory blood pressure; ACEI, angiotensin converting enzyme inhibitor; ARB, angiotensin receptor blocker; CCB, calcium channel blocker.

${ }^{a} p$ values for association between patients in on treatment group and newly diagnosed group.

${ }^{\mathrm{b}} \mathrm{OBP} 1$ and $\mathrm{OBP}_{2}$ defined as OBP measured before and after ABP measurement.

\section{RESULTS}

In the retrospective cohort, 903 patients had both OBP and ABP measurements. Among these, 565 patients (62.6\%) were newly diagnosed with hypertension (newly diagnosed group), whereas 338 patients (37.4\%) were previously on hypertensive medication (on-treatment group). Patients in the on-treatment group were older $(62.3 \pm 12.4$ years vs. $56.7 \pm 14.6$ years, $p<0.001)$ and were more likely to have diabetes mellitus (21\% vs. $11.5 \%, p<$ 0.001 ) and coronary artery disease (39.1\% vs. $16.5 \%, p<$ $0.001)$ than those in the newly diagnosed group. OBP1 was higher than ABP for both systolic $(138.4 \pm 17.8 \mathrm{mmHg}$ vs. $123.0 \pm 12.8 \mathrm{mmHg}, p<0.001)$ and diastolic $(83.7 \pm 11.8$ mmHg vs. $77.7 \pm 10.5 \mathrm{mmHg}, p<0.001)$ measurements. The most commonly prescribed anti-hypertensive agents were calcium-channel blocking agents (23.9\%), followed by angiotensin-receptor blockers (16.5\%) and $\beta$-blockers (15.0\%) (Table 1).

In the on-treatment group, $\mathrm{OBP} 1$ was higher than OBP2 in both systolic $(138.6 \pm 18.6 \mathrm{mmHg}$ vs. $134.4 \pm 16.6$ $\mathrm{mmHg}, p<0.001)$ and diastolic $(83.0 \pm 11.4 \mathrm{mmHg}$ vs. $80.7 \pm 10.9 \mathrm{mmHg}, p<0.001)$ measurements. In $41.7 \%$ of patients, the hypertensive medication was changed between $\mathrm{OBP} 1$ and $\mathrm{OBP} 2$, and as expected, $\mathrm{OBP} 2$ was lower than $\mathrm{OBP}_{1}$ in these patients. Interestingly, in patients without medication changes (58.3\%), OBP2 was also lower than was $\mathrm{OBP} 1$. In the newly diagnosed group, $38.8 \%$ of patients started taking hypertensive medication between $\mathrm{OBP}_{1}$ and $\mathrm{OBP} 2$. Similar to patients in the on-treatment group, $\mathrm{OBP} 2$ was lower than $\mathrm{OBP}_{1}$ in both patients with and without new hypertensive medication (Table 2).

The overall discordance rate was $43.9 \%, 43.5 \%$, and 
Table 2. The correlation of $\mathrm{OBP}_{1}$ and $\mathrm{OBP}_{2}$ in retrospective and prospective cohorts

\begin{tabular}{|c|c|c|c|c|c|c|}
\hline \multirow{2}{*}{ Variable } & \multicolumn{3}{|c|}{ SBP } & \multicolumn{3}{|c|}{$\mathrm{DBP}$} \\
\hline & $\mathrm{OBP}_{1}{ }^{\mathrm{a}}$ & $\mathrm{OBP}_{2}{ }^{\mathrm{a}}$ & $p$ value $^{\mathrm{b}}$ & $\mathrm{OBP}_{1}^{\mathrm{a}}$ & $\mathrm{OBP}_{2}{ }^{\mathrm{a}}$ & $p$ value $^{b}$ \\
\hline \multicolumn{7}{|l|}{ Retrospective cohort } \\
\hline Whole patients & $138.5 \pm 17.9$ & $134.4 \pm 16.6$ & $<0.001$ & $83.7 \pm 11.9$ & $82.1 \pm 11.2$ & $<0.001$ \\
\hline \multicolumn{7}{|l|}{ On-treatment group $(\mathrm{n}=338)$} \\
\hline Medication change (41.7\%) & $139.5 \pm 20.9$ & $133 \cdot 9 \pm 17 \cdot 2$ & 0.001 & $84.2 \pm 12.8$ & $81.5 \pm 11.9$ & 0.007 \\
\hline No medication change (58.3\%) & $137.9 \pm 16.6$ & $133.1 \pm 16.3$ & $<0.001$ & $82.1 \pm 10.2$ & $81.5 \pm 10.1$ & 0.004 \\
\hline \multicolumn{7}{|l|}{ Newly diagnosed group $(n=565)$} \\
\hline Medication start (38.8\%) & $142.0 \pm 17.4$ & $138.9 \pm 15.8$ & 0.003 & $86.9 \pm 12.1$ & $85.5 \pm 11.6$ & 0.030 \\
\hline Not on medication (61.2\%) & $136.1 \pm 17.2$ & $132.4 \pm 16.5$ & $<0.001$ & $82.3 \pm 11.7$ & $81.2 \pm 10.9$ & 0.037 \\
\hline \multicolumn{7}{|l|}{ Prospective cohort } \\
\hline Whole patients & $141.3 \pm 21.2$ & $136.1 \pm 19.2$ & 0.073 & $82.1 \pm 12.3$ & $79.5 \pm 13.0$ & 0.053 \\
\hline \multicolumn{7}{|l|}{ On-treatment group $(n=43)$} \\
\hline Medication change (39.5\%) & $136.5 \pm 26.8$ & $139.0 \pm 20.9$ & 0.605 & $78.0 \pm 13.3$ & $78.3 \pm 13.8$ & 0.874 \\
\hline No medication change (60.5\%) & $141.3 \pm 17 \cdot 5$ & $129.2 \pm 16.8$ & 0.006 & $80.3 \pm 8.1$ & $74.6 \pm 9.8$ & $<0.001$ \\
\hline \multicolumn{7}{|l|}{ Newly diagnosed group $(n=14)$} \\
\hline Medication start (64\%) & $148.8 \pm 9 \cdot 3$ & $143.2 \pm 12.2$ & 0.205 & $90.3 \pm 10.2$ & $89.9 \pm 9.6$ & 0.883 \\
\hline Not on medication (36\%) & $144.0 \pm 33.6$ & $150.0 \pm 25.5$ & 0.710 & $90.0 \pm 21.3$ & $90.4 \pm 16.8$ & 0.969 \\
\hline
\end{tabular}

Values are presented as mean $\pm \mathrm{SD}$.

OBP, office blood pressure; SBP, systolic blood pressure; DBP, diastolic blood pressure.

${ }^{\mathrm{a}} \mathrm{OBP} 1$ and $\mathrm{OBP} 2$ defined as OBP measured before and after ambulatory blood pressure measurement.

${ }^{\mathrm{b}} \mathrm{p}$ values for paired $t$ test between $\mathrm{OBP} 1$ and $\mathrm{OBP} 2$.

44.5\% in all, newly diagnosed and on-treatment patients, respectively. In the newly diagnosed group, the rate of white coat hypertension was $20.1 \%$, while that of masked hypertension was $23.4 \%$. In the on-treatment group, the rate of over-treatment was $24.9 \%$, while that of under-treatment was $19.6 \%$ (Fig. 1). The correlation was weak between systolic OBP1 and $\mathrm{ABP}\left(r^{2}=0.038, p<\right.$ 0.001) and systolic OBP2 and ABP $\left(r^{2}=0.079, p<0.001\right)$. In identifying hypertension, the area under the curves (AUCs) of OBP1 and OBP2 were 0.57 (95\% confidence interval [CI], 0.53 to 0.60 ) and 0.64 (95\% CI, 0.60 to 0.68 ), respectively (Fig. 2). The overall diagnostic accuracy of OBP1 was $56.1 \%$, with a sensitivity of $51.1 \%$ and a specificity of $60.2 \%$, and that of OBP2 was $62.7 \%$, with a sensitivity of $47.4 \%$ and a specificity of $75 \%$ (Table 3 ).

A total of 57 patients were included in the prospective cohort: 43 patients (75\%) were in the on-treatment group and 14 patients $(24.5 \%)$ were in the newly diagnosed group. The baseline characteristics were comparable between both groups (Table 1). The correlation between $\mathrm{OBP} 1$ and $\mathrm{OBP} 2$ was similar to that of the retrospective cohort. The overall systolic $(141.3 \pm 21.2$ vs. $135.3 \pm 18.4$, $p=0.073)$ and diastolic $(82.0 \pm 12.2$ vs. $79.5 \pm 13.1, p=0.053)$ $\mathrm{OBP} 1$ tended to be higher than did OBP2 (Table 2). The correlation between $\mathrm{OBP} 1$ and $\mathrm{ABP}\left(r^{2}=0.046, p=0.108\right)$ was weak. The discordance rate between $\mathrm{OBP} 1$ and $\mathrm{ABP}$ was $68.4 \%$, of which $43.8 \%$ were false positive and $24.6 \%$ were false negative results. In identifying hypertension, the AUCs of OBP1 and OBP2 were 0.51 (95\% CI, 0.36 to $0.67 ; p=0.88$ ) and 0.67 (95\% CI, 0.53 to $0.81 ; p=0.03$ ), respectively.

When stratifying according to sex, the proportion of false negative results (i.e., masked and under-treated hypertension) was higher in men than in women $(26.1 \%$ vs. $17.8 \%, p=0.003$, whereas that of false positive results (i.e., white-coat or over-treated hypertension) was higher in female than in male patients $(28.7 \%$ vs. $15.2 \%, p<$ o.001) (Fig. 3). 

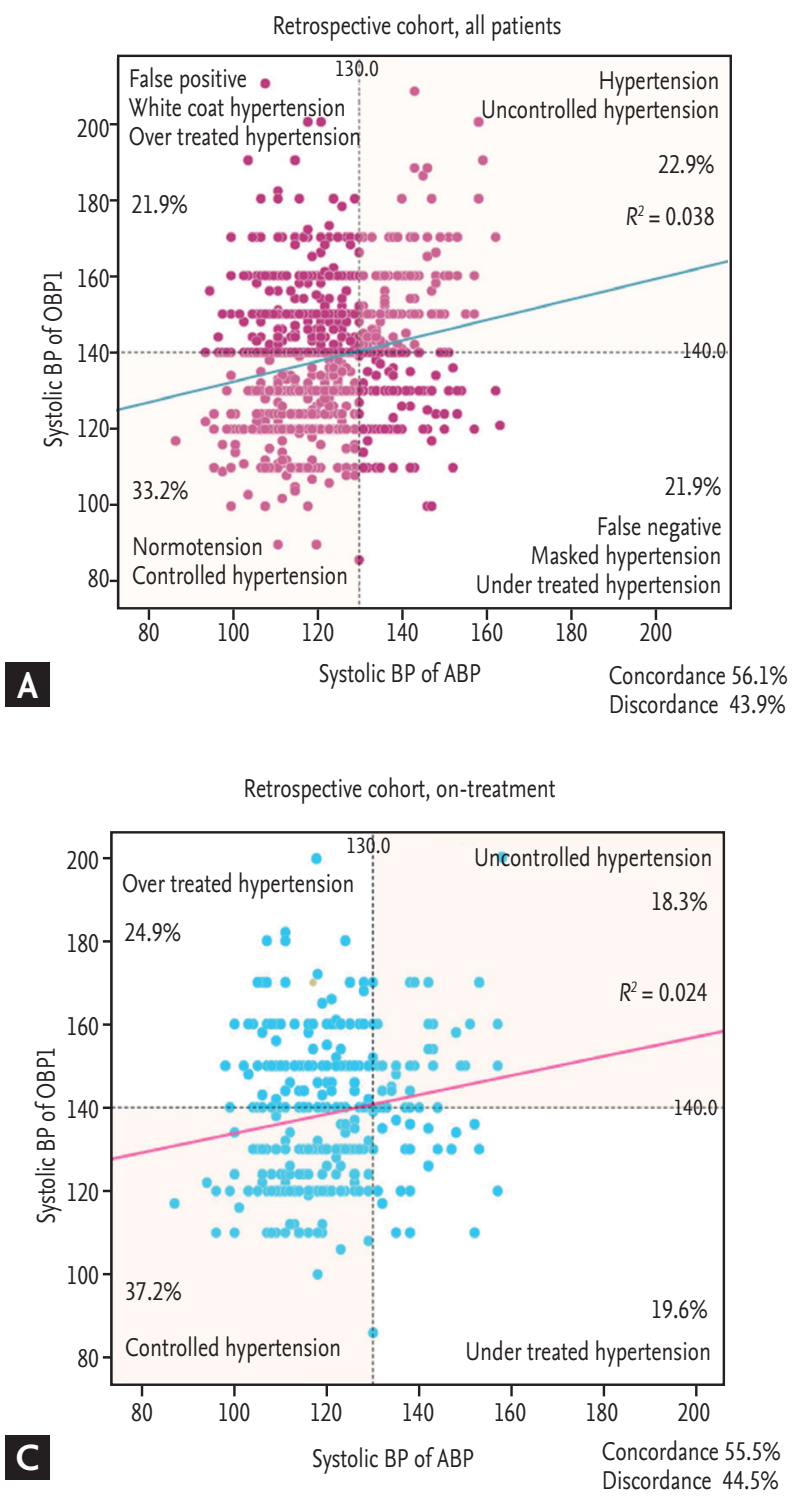
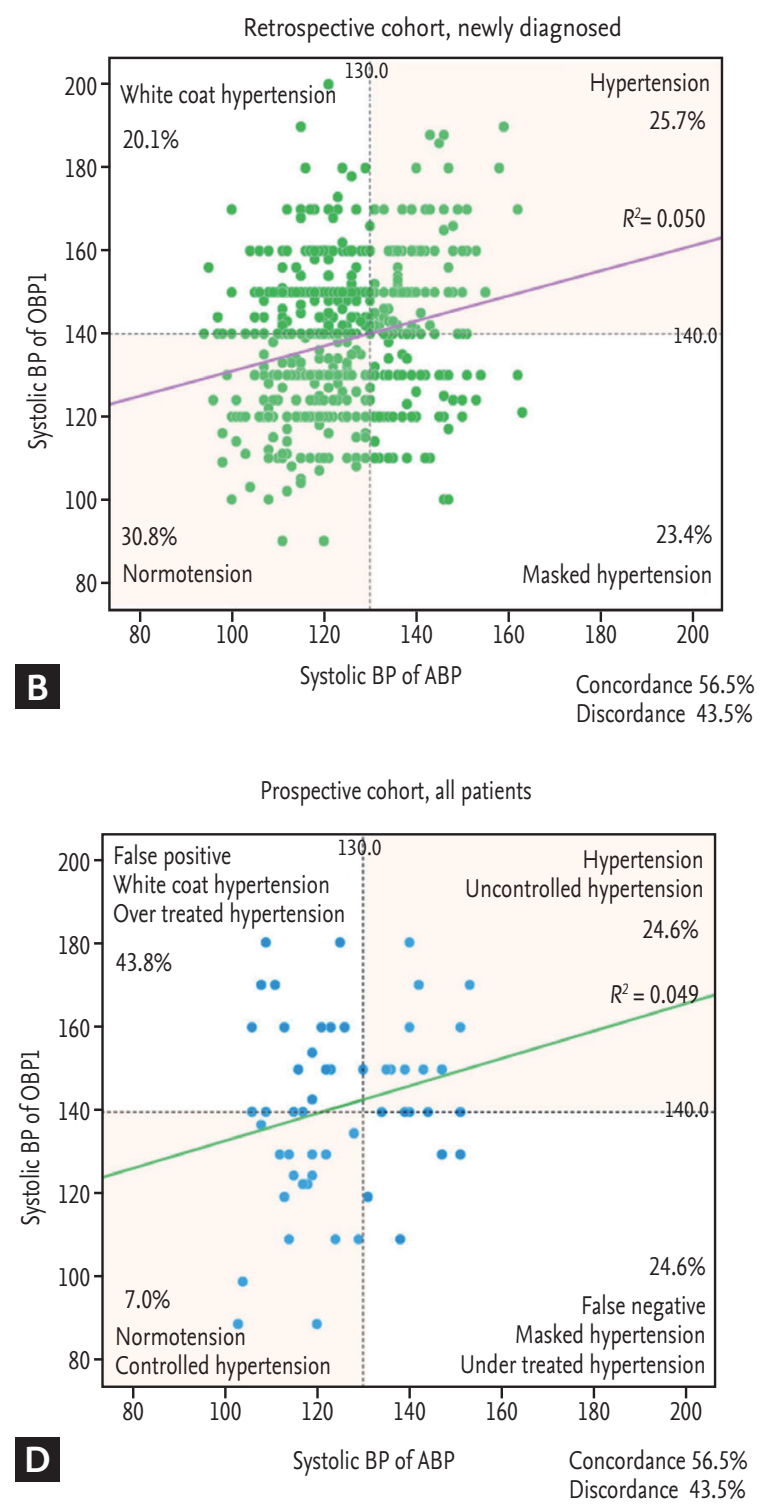

Figure 1. Correlation between office blood pressure (OBP) and ambulatory blood pressure (ABP) in (A) all patients in the retrospective cohort, (B) patients in the newly-diagnosed group in the retrospective cohort, (C) patients in the on-treatment group in the retrospective cohort, and (D) all patients in the prospective cohort. BP, blood pressure; $\mathrm{OBP} 1$, before $\mathrm{ABP}$ measurement.

Table 3. The diagnostic accuracy of office blood pressure

\begin{tabular}{lcccccccc}
\hline & Sensitivity, \% & Specificity, \% & PPV, \% & NPV, \% & PLR & NLR & Overall accuracy, \% \\
\hline $\mathrm{OBP}_{1}{ }^{\mathrm{a}}$ & 51.1 & 60.2 & 51.1 & 60.2 & 1.29 & 0.81 & 56.1 & \\
$\mathrm{OBP}_{2}{ }^{\mathrm{a}}$ & 47.4 & 75 & 60.7 & 63.6 & 1.9 & 0.7 & 62.7 \\
\hline
\end{tabular}

PPV, positive predictive value; NPV, negative predictive value; PLR, positive likelihood ratio; NLR, negative likelihood ratio; OBP, office blood pressure.

${ }^{\mathrm{a} O B P 1}$ and $\mathrm{OBP}_{2}$ defined as OBP measured before and after ambulatory blood pressure measurement. 


\section{DISCUSSION}

In this study, we evaluated the diagnostic accuracy of manual OBP measurements in reference to ABP in ambulatory hypertensive patients. We showed that there is only a weak correlation between OBP and ABP, and that OBP has a low diagnostic accuracy. We also showed that $\mathrm{OBP} 2$ was lower than $\mathrm{OBP} 1$ regardless of medication

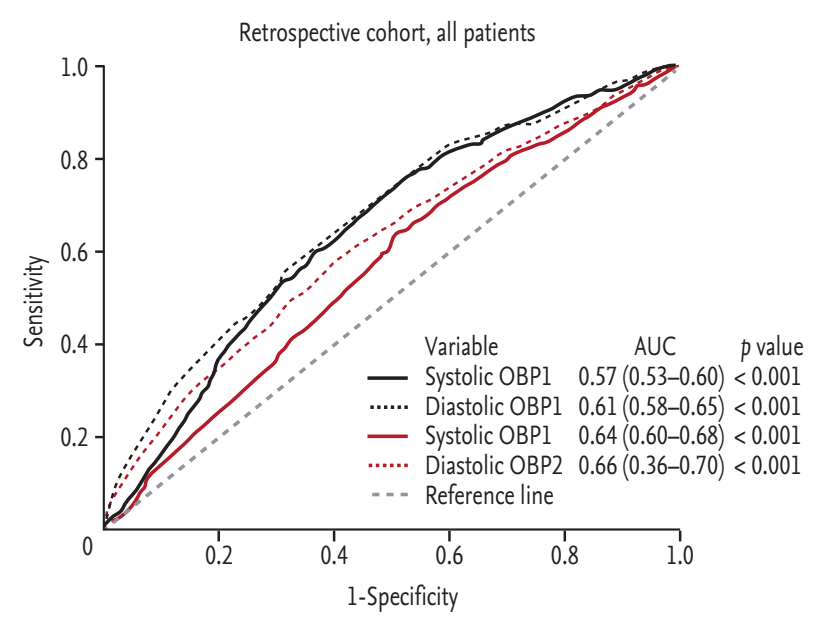

Figure 2. The diagnostic value of office blood pressure (OBP) in all patients in the retrospective cohort. OBP1 and $\mathrm{OBP}_{2}$ defined as OBP measured before and after ambulatory blood pressure measurement. AUC, area under the curve. use, and that male patients were prone to masked hypertension, whereas female patients were susceptible to white coat hypertension.

The most important finding was the low diagnostic accuracy of OBP in identifying hypertension in ambulatory patients. With regard to $\mathrm{ABP}$ as a reference in BP measuring methods, hypertension diagnosed using $\mathrm{OBP} 1$ was incorrect in almost half of the patients (discordance rate, 43.9\%). Moreover, OBPı had a low AUC of 0.57 (95\% CI, 0.53 to 0.60 ), thereby suggesting that OBP may have limited value in accurately diagnosing hypertension and reliable treatment monitoring [21-23]. We observed similar results in the prospective cohorts. Therefore, we believe that this finding represents true practice and strengthens our study results. A possible explanation for the low diagnostic accuracy of OBP may be the complexity of the measuring technique and variations in BP due to underlying circumstances in the outpatient clinic [6].

Another interesting finding was that $\mathrm{OBP}_{2}$ was lower than OBP1 in all circumstances. Furthermore, OBP2 had a slightly higher AUC 0.64 (95\% CI, 0.60 to 0.67 ) and better correlation with $\mathrm{ABP}\left(r^{2}=0.079, p<0.001\right)$ than did OBP1. By definition, OBP2 for all patients was measured after $A B P$ and physicians were aware of $A B P$ results. Therefore, it is possible that the physician's man-
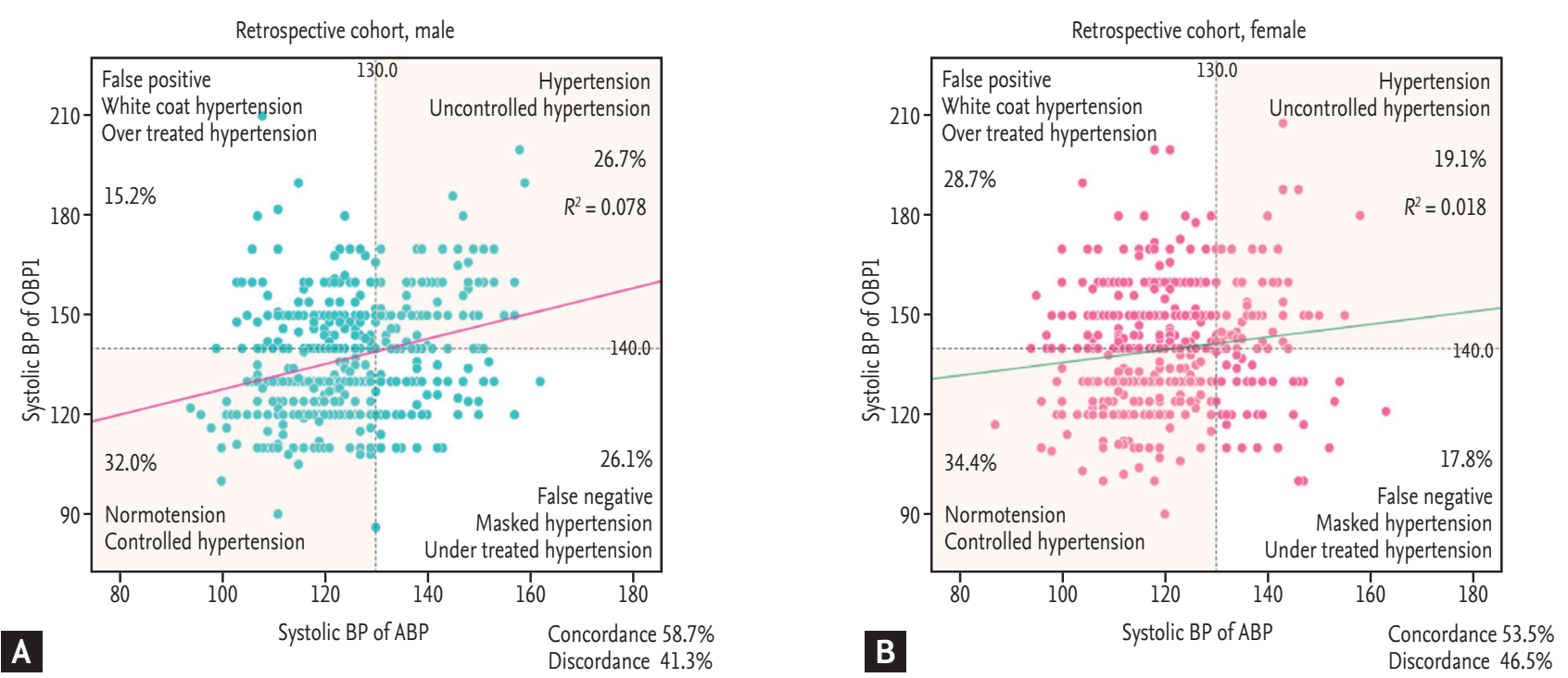

Figure 3. Correlation between office blood pressure (OBP) and ambulatory blood pressure (ABP) according to sex in (A) male patients and (B) female patients. BP, blood pressure; $\mathrm{OBP}_{1}$, before $\mathrm{ABP}$ measurement. 
ual BP measurement was influenced by the ABP results. The physician may take $\mathrm{BP}$ values that are closer to $\mathrm{ABP}$ results, which is a potential bias in manual OBP measurement.

The rate of false negative results (i.e., masked or under-treated hypertension) was $21.9 \%$ in this study. It was higher in men $(26.1 \%)$ than in women $(17.8 \%)[24,25]$. Masked and under-treated hypertension are both clinical conditions in which the patient receives suboptimal treatment and, consequently, has an increased risk for cardiovascular complications [26]. In contrast, female patients had higher false positive results (i.e., white-coat or over-treated hypertension) [24]. The reason for this sex difference in susceptibility to false positive and negative results is presently unclear.

The high discordance rate has an essential impact on health care policy. Patients with false positive results take unnecessary antihypertensive drugs, not only causing financial burden, but also exposing patients to the risk of hypotension. Similarly, false negative results are a potential risk for increased cardiovascular events. The manual BP measurement is the most widely used BP measuring method in daily practice [5]; however, our current finding encourages the use of ABP for diagnosis and treatment monitoring in ambulatory hypertensive patients. Although we showed that the discordance rate in both retrospective and prospective cohorts is high, we did not provide data on clinical outcome. While ABP and cardiovascular events have been highly correlated $[25,27]$, and ABP has been shown to predict cardiovascular outcomes better than does OBP in high-risk patients with type 2 diabetes mellitus [28], it is unknown whether patients with OBP-guided hypertension treatment have worse outcomes than do those with ABP-guided management. Since patients were enrolled at a tertiary referral center, it is unknown whether the study results can be directly extrapolated to all patients, especially to those treated in the primary care setting. Finally, there was a significant difference in time interval between $\mathrm{OBP} 1$ and $\mathrm{ABP}$ versus $\mathrm{ABP}$ and $\mathrm{OBP} 2$ (49.2 \pm 87.0 days vs. $10.0 \pm 10.6$ days, $p=0.001$ ). This may partly account for the higher AUC of $\mathrm{OBP}_{2}$ compared with $\mathrm{OBP} 1$, regardless of the medication change.

\section{KEY MESSAGE}

1. There is only a weak correlation between office blood pressure (OBP) and ambulatory blood pressure $(\mathrm{ABP})\left(r^{2}=0.038, p<0.001\right)$. The overall discordance rate of OBP compared with $\mathrm{ABP}$, the reference methods for measuring blood pressure, was $43.9 \%$, while manual OBP has a low diagnostic accuracy of $56 \%$.

2. In subgroup analysis, male patients were prone to masked hypertension, whereas female patients were susceptible to white coat hypertension.

3. Our findings encourage the use of ABP for diagnosis and treatment monitoring of ambulatory hypertensive patients.

\section{Conflict of interest}

No potential conflict of interest relevant to this article was reported.

\section{Acknowledgments}

The current work was supported by the Centers for Disease Control and Prevention, Ministry of Health and Welfare, Republic of Korea (Grant no. 2013-E63010-01). The electronic CRF development and data management for this study was performed using iCReaT (internet-based Clinical Research and Trial management system), a data management system established by the Centers for Disease Control and Prevention, Ministry of Health and Welfare, Republic of Korea.

\section{REFERENCES}

1. Kannel WB. Some lessons in cardiovascular epidemiology from Framingham. Am J Cardiol 1976;37:269-282.

2. Wilson PW, D'Agostino RB, Levy D, Belanger AM, Silbershatz H, Kannel WB. Prediction of coronary heart disease using risk factor categories. Circulation 1998;97:1837-1847.

3. Lewington S, Clarke R, Qizilbash N, Peto R, Collins R; Prospective Studies Collaboration. Age-specific relevance of usual blood pressure to vascular mortality: a meta-analysis of individual data for one million adults in 61 prospective studies. Lancet 2002;360:1903-1913.

4. James PA, Oparil S, Carter BL, et al. 2014 Evidence-based 
guideline for the management of high blood pressure in adults: report from the panel members appointed to the Eighth Joint National Committee (JNC 8). JAMA 2014;311:507-520.

5. Lee HY, Park JB. The Korean Society of Hypertension guidelines for the management of hypertension in 2013: its essentials and key points. Pulse (Basel) 2015;3:21-28.

6. Coogan N, Marra A, Lomonaco EA. Assessing accurate BP measurement: size and technique matter! Nursing 2015;45:16-18.

7. Myers MG. The great myth of office blood pressure measurement. J Hypertens 2012;30:1894-1898.

8. Vinyoles E, Camafort M, Domenech M, Coca A, Sobrino J; ESTHEN group investigators. Prevalence of masked uncontrolled hypertension according to the number of office blood pressure measurements. Rev Clin Esp 2015;215:425-430.

9. Campbell NR, Culleton BW, McKay DW. Misclassification of blood pressure by usual measurement in ambulatory physician practices. Am J Hypertens 2005;18:1522-1527.

10. Little P, Barnett J, Barnsley L, Marjoram J, Fitzgerald-Barron A, Mant D. Comparison of agreement between different measures of blood pressure in primary care and daytime ambulatory blood pressure. BMJ 2002;325:254.

11. Parati G, Stergiou G, O’Brien E, et al. European Society of Hypertension practice guidelines for ambulatory blood pressure monitoring. J Hypertens 2014;32:1359-1366.

12. Smulyan H, Safar ME. Blood pressure measurement: retrospective and prospective views. Am J Hypertens 2011;24:628-634.

13. Krause T, Lovibond K, Caulfield M, McCormack T, Williams B; Guideline Development Group. Management of hypertension: summary of NICE guidance. BMJ 2011;343:d4891.

14. Shimamoto K, Ando K, Fujita T, et al. The Japanese Society of Hypertension guidelines for the management of hypertension (JSH 2014). Hypertens Res 2014;37:253-390.

15. Daskalopoulou SS, Rabi DM, Zarnke KB, et al. The 2015 Canadian Hypertension Education Program recommendations for blood pressure measurement, diagnosis, assessment of risk, prevention, and treatment of hypertension. Can J Cardiol 2015;31:549-568.

16. Kim SG. Clinical implications of ambulatory and home blood pressure monitoring. Korean Circ J 2010;40:423-431.

17. Yoo WS, Park HJ, Lee EY, Choi SK. A representative value for 24-hour monitored ambulatory blood pressure. J Korean Med Sci 1986;1:59-62.
18. O'Brien E, Parati G, Stergiou G, et al. European Society of Hypertension position paper on ambulatory blood pressure monitoring. J Hypertens 2013;31:1731-1768.

19. Mancia G, Fagard R, Narkiewicz K, et al. 2013 ESH/ESC guidelines for the management of arterial hypertension: the Task Force for the management of arterial hypertension of the European Society of Hypertension (ESH) and of the European Society of Cardiology (ESC). J Hypertens 2013;31:1281-1357.

20. O'Brien E, Asmar R, Beilin L, et al. European Society of Hypertension recommendations for conventional, ambulatory and home blood pressure measurement. J Hypertens 2003;21:821-848.

21. Sebo P, Pechere-Bertschi A, Herrmann FR, Haller DM, Bovier P. Blood pressure measurements are unreliable to diagnose hypertension in primary care. J Hypertens 2014;32:509-517.

22. Sendra-Lillo J, Sabater-Hernandez D, Sendra-Ortola A, Martinez-Martinez F. Agreement between community pharmacy, physician's office, and home blood pressure measurement methods: the PALMERA study. Am J Hypertens 2012;25:290-296.

23. Banegas JR, Ruilope LM, de la Sierra A, et al. High prevalence of masked uncontrolled hypertension in people with treated hypertension. Eur Heart J 2014;35:3304-3312.

24. Hwang ES, Choi KJ, Kang DH, et al. Prevalence, predictive factor, and clinical significance of white-coat hypertension and masked hypertension in Korean hypertensive patients. Korean J Intern Med 2007;22:256-262.

25. Conen D, Aeschbacher S, Thijs L, et al. Age-specific differences between conventional and ambulatory daytime blood pressure values. Hypertension 2014;64:1073-1079.

26. Ohkubo T, Kikuya M, Metoki H, et al. Prognosis of "masked" hypertension and "white-coat" hypertension detected by 24 -h ambulatory blood pressure monitoring 10-year follow-up from the Ohasama study. J Am Coll Cardiol 2005;46:508-515.

27. Clement DL, De Buyzere ML, De Bacquer DA, et al. Prognostic value of ambulatory blood-pressure recordings in patients with treated hypertension. N Engl J Med 2003;348:2407-2415.

28. Salles GF, Leite NC, Pereira BB, Nascimento EM, Cardoso CR. Prognostic impact of clinic and ambulatory blood pressure components in high-risk type 2 diabetic patients: the Rio de Janeiro type 2 diabetes cohort study. J Hypertens 2013;31:2176-2186. 